\title{
Assessment of the Effect of Cyclic Irrigation on Reducing Nitrogen Effluent Loading from a Paddy-Field District
}

\author{
Takehide HAMA*, Katsuyuki OSUGA**, Sho SUGIYAMA***, Daichi IWASAKI****, \\ Takeru AOKI***** \\ *Graduate School of Science and Technology, Kumamoto University, 2-39-1 Kurokami, \\ Chuo Ward, Kumamoto 860-8555, Japan \\ **Shiga Prefectural Government, 4-1-1 Kyomachi, Otsu City, Shiga 520-8577, Japan \\ ***Kubota Corp., 2-47-1, Shikitsu-higashi, Naniwa Ward, Osaka 556-8601, Japan \\ ****Graduate School of Agriculture, Kyoto University, Kitashirakawa Oiwakecho, Sakyo Ward, \\ Kyoto 860-8502, Japan \\ *****Tokyo Gas Co., Ltd., 1-5-20 Kaigan, Minato Ward, Tokyo 105-8527, Japan
}

\begin{abstract}
Nitrogen $(\mathrm{N})$ effluent loading discharged from paddy fields has a large impact on water quality in downstream areas. Cyclic irrigation, which reuses drainage water for irrigation purposes, is considered an effective water pollution prevention measure in paddy fields. In this study, we evaluated the effectiveness of cyclic irrigation in the reduction of $\mathrm{N}$ loading from a paddy-field district. We measured temporal variations in $\mathrm{N}$ concentration in drainage water and estimated the $\mathrm{N}$ mass balance for the study district for three consecutive years since 2007 . We found that cyclic irrigation reduced $\mathrm{N}$ loadings. Mean $\mathrm{N}$ effluent loadings during the cyclic irrigation were 4.4 $\mathrm{kg} / \mathrm{ha}$ and were smaller compared to lake water irrigation (non-cyclic irrigation). The hydrological structure and effect of a cyclic irrigation system can be characterized by using three parameters: ratio of the $\mathrm{N}$ concentration in drainage water to that in irrigation water; intensity at which drainage water is reused; and ratio of surplus irrigation water to the total amount of irrigation water. We conclude that the efficient use of irrigation water is important for reducing $\mathrm{N}$ effluent loadings from the paddy-field district because $\mathrm{N}$ in drainage water may not be qualitatively purified.
\end{abstract}

Keywords: nitrogen, paddy field, water reuse

\section{INTRODUCTION}

The removal of pollutants such as suspended solids, nutrients, and organic matter from non-point sources is an important issue in water quality management, especially in downstream watersheds. Paddy-field districts, which use large quantities of water, are major non-point sources for these types of pollutants. Cyclic irrigation, which reuses drainage water for irrigation, is considered an effective water management technique for reducing pollutants from these areas. Cyclic irrigation can reduce pollutant loadings in multiple ways. For example, with this technique, more water is retained within paddy fields, thus reducing the volume of run-off carrying potential pollutants. In addition, water that does leave the fields is partially purified because longer hydraulic retention time allows for the increased absorption of nutrients within fields, reducing the amount that is released as pollutants (Takeda et al., 1997; Feng et al., 2004, 2005; Takeda and Fukushima, 2004, 2006). The effectiveness of cyclic irrigation is directly proportional to the amount of water that is reused (Kaneki, 2003) and to the intensity of cyclic irrigation (Shiratani et al., 2004; Hitomi et al., 2006). However, because high intensity cyclic irrigation requires the use of large quantities of freshwater to reduce the risks

Address correspondence to Takehide Hama, Graduate School of Science and Technology, Kumamoto University, Email: hama@kumamoto-u.ac.jp

Received May 7, 2012, Accepted July 24, 2012. 
associated with pathogens and heavy metals (Zulu et al., 1996), there is a low upper limit to the intensity used in many paddy-field districts that attempt to capture industrial or domestic wastewater from upstream areas. Accordingly, little is known about the effectiveness of using high intensity cyclic irrigation to reduce nutrient effluent loadings from paddy-field districts.

Our objectives in this study were to understand the characteristics of nitrogen $(\mathrm{N})$ effluent loading in a low-lying paddy-field district currently implementing cyclic irrigation with high intensity and to evaluate the effectiveness of that technique in reducing the loadings. We focused our analysis, over three years $(2007-2009)$, on a low-lying paddy-field district neighboring Lake Biwa, the largest lake in Japan.

\section{MATERIALS AND METHODS}

\section{Study Site}

We focused our analysis on a low-lying paddy-field district located on the southeastern edge of Lake Biwa $\left(35^{\circ} 05^{\prime} \mathrm{N}, 135^{\circ} 56^{\prime} \mathrm{E}\right.$, Fig. 1). The district covers an area of about $1.5 \mathrm{~km}^{2}$, with more than $90 \%$ of that area comprised of paddy fields. Rotation crops, specifically wheat and soybean, are grown in about one-third of the paddy area on a three-year cycle.

Within the district, a complex drainage and irrigation system in which canals are separate for each process were employed. Furthermore, industrial or domestic wastewater from outside the district does not flow into the drainage and irrigation canals. The drainage portion of the system contains one main and 14 lateral canals, and drainage water is discharged through floodgates at both ends of the main canal. During our study period, the floodgate at the northern end of the main drainage canal was closed, forcing the outflow of all drainage water through the southern floodgate. Two pump stations are located at the northern and southern ends of the main drainage canal with maximum capacities of approximately $2.5 \times 10^{3}$ and $0.2 \times 10^{3} \mathrm{~m}^{3} / \mathrm{h}$, respectively. The northern pump station has two water inlets that connect to Lake Biwa and to the main drainage canal, whereas the southern pump station has a single water inlet that only connects to the main drainage canal. Because there are no water sources other than Lake Biwa, the maximum amount of available water for irrigation depends solely on the capacity of these pumps.

In this region, two irrigation techniques are used at specific times of the year during a four-month irrigation period (Table 1). Cyclic irrigation is employed for the first half of the season and uses recycled drainage water to flood the paddy fields. When the drainage water level falls by evapotranspiration, water flows from the lake to the drainage canal through the floodgate. Lake water irrigation is then used for the second half of the irrigation period, when cool water is needed for maximum rice quality, in which irrigation water is pumped directly from Lake Biwa through the northern pump. A 10-day mid-summer drainage season separates the use of these irrigation techniques.

\section{Water Quality and Hydrological Measurements}

We measured the quality of drainage, irrigation, and lake water at weekly intervals from 2007 to 2009. Samples of drainage and irrigation water were obtained from the southern 


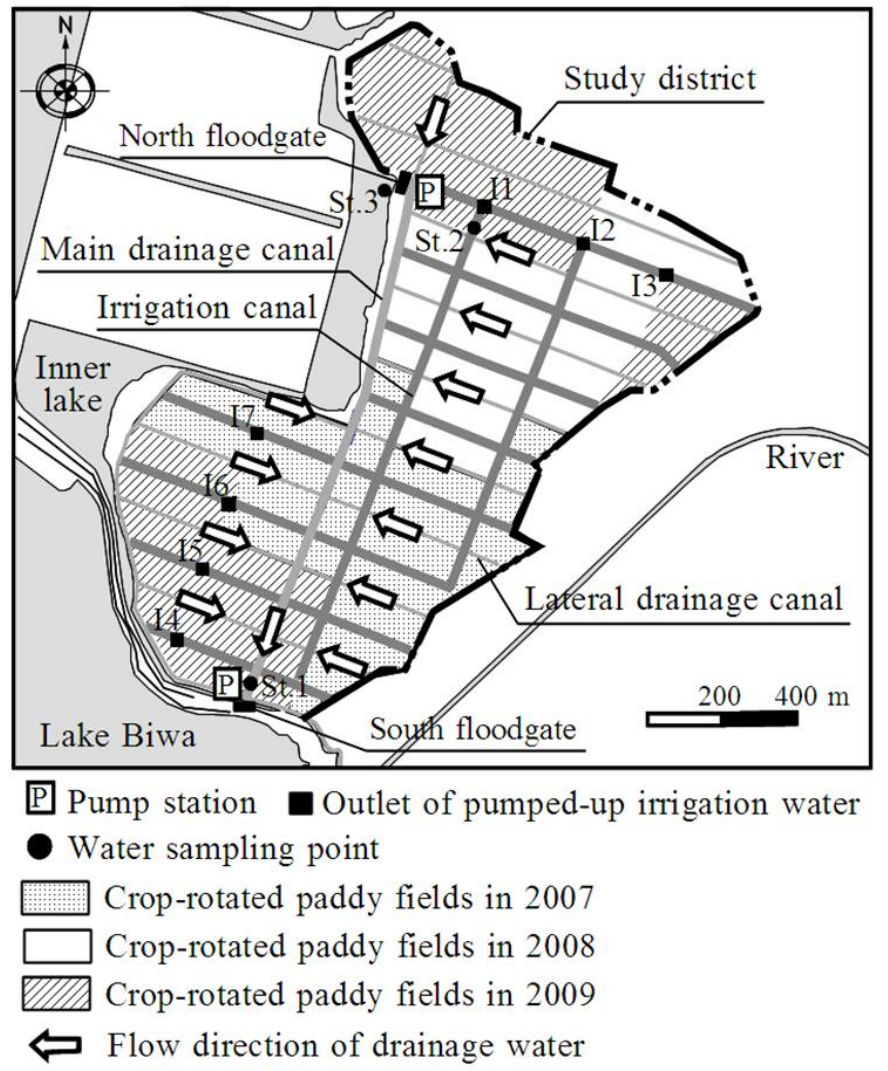

Fig. 1 - Layout of paddy fields, pump stations, and irrigation and drainage canals in the study district $\left(35^{\circ} 05^{\prime} \mathrm{N}, 135^{\circ} 56^{\prime} \mathrm{E}\right)$.

Table 1 - Irrigation schedule in the study district.

\begin{tabular}{cccc}
\hline Irrigation schedule & 2007 & 2008 & 2009 \\
\hline Start of irrigation & April 25 & April 26 & April 24 \\
Cyclic irrigation period & April 25 - June 23 & April 26 - June 24 & April 24 - June 25 \\
Mid-summer drainage season & June 24- July 5 & June 25 - July 6 & June 26 - July 9 \\
Lake water irrigation period & July 6- August 28 & July 7 - August 26 & July 10 - September 2 \\
End of irrigation & August 28 & August 26 & September 2 \\
\hline
\end{tabular}

end of the main drainage canal and the outlet of the pump, respectively, and samples of inner lake water were obtained. In addition, a programmable automatic water sampler (3700 Sampler, Teledyne Isco Inc., Lincoln, NE, USA) was installed at the southern end of the main drainage canal to sample drainage water daily at noon. Rainwater collected in a small plastic tank at the northern pump station was sampled during weekly field visits. All sampled water was analyzed for total nitrogen (TN) using an ultraviolet spectrophotometer (UV-1200, Shimadzu Corp., Kyoto, Japan) after alkaline potassium-peroxydisulfate digestion.

We installed meteorological instruments for measuring rainfall, air temperature, wind velocity, relative humidity, and solar radiation in an open area at the southern pump 
station. We estimated evapotranspiration during the irrigation period by the Penman method (Penman, 1948) using the data measured at the southern pump station and the crop coefficient value for rice (Sakuratani and Horie, 1985). We measured the flow rates of discharged drainage water (lake water irrigation period) and of inflowing lake water (cyclic irrigation period) using flow meters (2150 Area Velocity Flow Module, Teledyne Isco Inc.) installed at both ends of the main drainage canal. We estimated the volume of pumped water by multiplying the amount of time the pumps were in operation by their capacities. We did not measure the subsurface percolation from the district but assumed it to be negligible because it is a low-lying district and is close to the lake with high groundwater levels. We calculated the water balance over a fixed portion of each part of the irrigation period in order to compare values across years; water balance for the cyclic irrigation period was measured from 20 April to 30 June and from 1 July to 30 September for the lake water irrigation period.

\section{Simple Model for Assessment of Cyclic Irrigation}

In this study, we determined the net $\mathrm{N}$ export as a way of assessing the effect of irrigation techniques on the reduction in effluent loading in the district, where the net $\mathrm{N}$ export is defined as $\mathrm{N}$ export subtracting $\mathrm{N}$ input. Because $\mathrm{N}$ loading is dependent on both $\mathrm{N}$ concentration and water flow volume, we define the net $\mathrm{N}$ export, $L_{\text {net }}(\mathrm{kg} / \mathrm{ha} / \mathrm{d})$, as:

$$
L_{\text {net }}=C_{\text {out }} Q_{\text {out }}-C_{\text {in }} Q_{\text {in }}
$$

where $C$ is the $\mathrm{N}$ concentration $(\mathrm{mg} / \mathrm{L})$ and $Q$ is the water flow volume $(\mathrm{mm} / \mathrm{d})$. The subscripts out and in refer to the outflow from and inflow into the district, respectively. In this case, $C_{\text {out }}$ is the $\mathrm{N}$ concentration of the drainage water; $Q_{\text {out }}$ is the amount of drainage water discharged from the district; $C_{\text {in }}$ is the $\mathrm{N}$ concentration of the lake water; and $Q_{\text {in }}$ is the amount of lake water intake. A value of $L_{\text {net }}$ greater than zero indicates that the district is adding to $\mathrm{N}$ effluent loading downstream (contamination) while a value less than zero indicates that the district is reducing it (purification). Considering the neutral condition, where $L_{\text {net }}=0$, this relationship can be shown as follows:

$$
C_{\text {out }} / C_{\text {in }}=Q_{\text {in }} / Q_{\text {out }}
$$

where we define $C_{\text {out }} / C_{\text {in }}$ as the concentration ratio, $\chi_{\mathrm{c}}$.

We were able to determine the values of each variable needed to calculate net $\mathrm{N}$ export through a conceptual understanding of the relationships between water flows in this system (Fig. 2). Because this system uses a closed irrigation canal, we derived the volume of irrigation water $\left(Q_{\mathrm{p}}\right)$ directly from the volume of water that is passed through the pump. The inflow of water from the lake $\left(Q_{\text {in }}\right)$ can then be calculated by multiplying the volume of irrigation water by the proportion of water that is not reused through cyclic irrigation:

$$
Q_{\text {in }}=\left(1-\alpha_{\mathrm{CI}}\right) Q_{\mathrm{p}}
$$

where $\alpha_{\mathrm{CI}}$ is the cyclic irrigation ratio, defined as the ratio of the amount of reused water to the total amount of irrigation water (Hama et al., 2010). However, equation 3 is not 
necessarily true for the district. If the inlet to the lake at the northern pump is closed, lake water does not directly flow into the pump but into the main drainage canal under cyclic irrigation; in other words, equation 3 may be true when the lakeside inlet is opened. The amount of drainage water that is discharged from the district $\left(Q_{\text {out }}\right)$ can be calculated as a function of both the ratio of water that is considered surplus irrigation water not used in the paddy fields $\left(\alpha_{\mathrm{SW}}\right)$ and the ratio of water that is reused in the process of cyclic irrigation:

$$
Q_{\text {out }}=\left(\alpha_{\mathrm{SW}}-\alpha_{\mathrm{CI}}\right) Q_{\mathrm{p}}
$$

This model does not consider temporary deficits in the inflow of water, which can lead to a decrease in the amount of drainage water stored in the drainage canal. As noted previously, when the amount of drainage water in the canal falls (alternatively when $\alpha_{\mathrm{SW}}$ $<\alpha_{\mathrm{CI}}$ in equation 4), water must be brought in from the lake. In this case, when the lakeside inlet at the northern pump is closed as was the case during cyclic irrigation periods in 2008 and 2009, the net $\mathrm{N}$ export can be described as a negative net export:

$$
L_{\mathrm{net}}=-\left(1-\alpha_{\mathrm{SW}}\right) C_{\mathrm{in}} Q_{\mathrm{in}}<0 \text { for any } \alpha_{\mathrm{CI}}
$$

and cyclic irrigation may always show a net purification effect.

Knowing the relationships between water flows in our model (Fig. 2) as described above, we can replace the variables on the right side of equation 2 with the relationships established in equations 3 and 4 :

$$
\beta=\left(1-\alpha_{\mathrm{CI}}\right) /\left(\alpha_{\mathrm{SW}}-\alpha_{\mathrm{CI}}\right)
$$

where $\beta$ varies as a function of both $\alpha_{\mathrm{CI}}$ and $\alpha_{\mathrm{SW}}$. Using this information, we can show the effect of irrigation on $L_{\text {net }}$ for a given $\alpha_{\text {SW }}$ value (Fig. 3). The irrigation system has a net contamination effect when $\chi_{c}$ is above the $\beta$ curve and a net purification effect when $\chi_{c}$ is below that curve. In addition, when $\chi_{c}$ is less than one, irrigation for any $\alpha_{C I}$ may show a net purification effect of irrigation because $\beta$ is greater than or equal to 1 for any combination of $\alpha_{C I}$ and $\alpha_{S W}$. This simple model allows us to establish the effect of cyclic irrigation on $\mathrm{N}$ effluent loadings considering various irrigation intensities, assuming the conditions of our particular irrigation system.

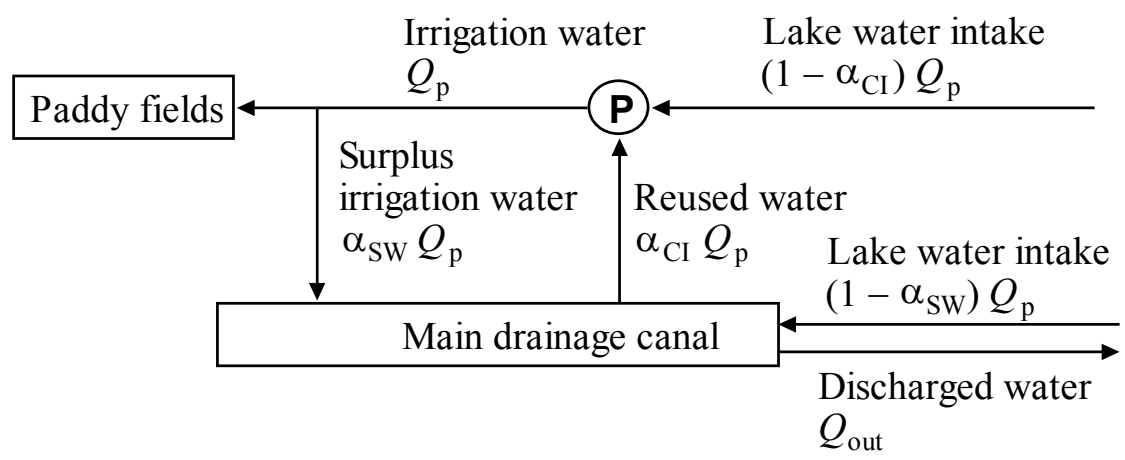

Fig. 2 - Conceptual diagram of water flow under cyclic irrigation in the paddy-field district. Upper-case "P" represents a pump and arrows indicate flow direction. 


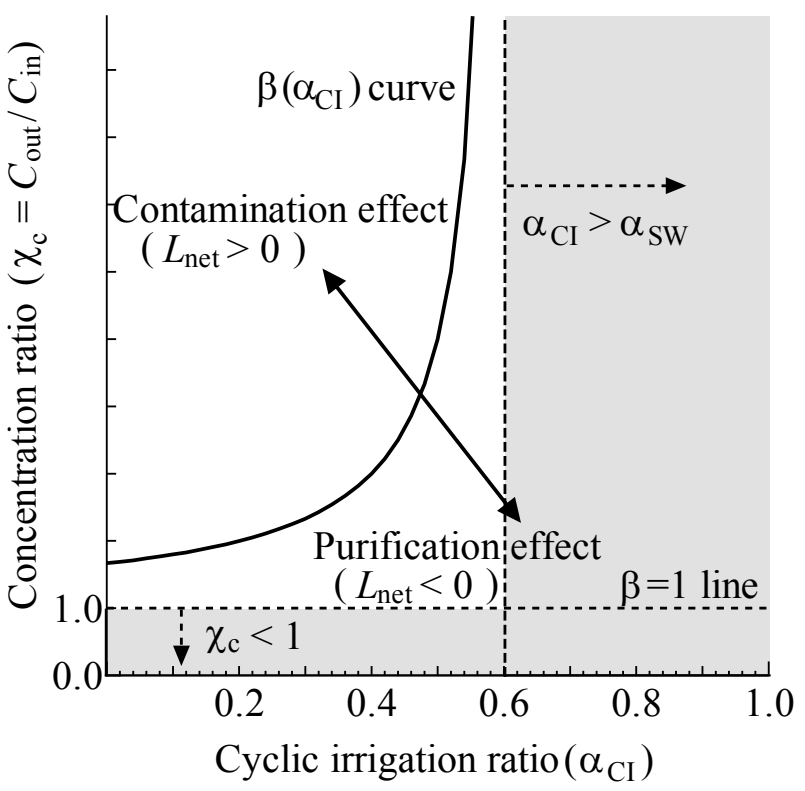

Fig. 3 - Neutral effect curve for net effluent loadings at a given surplus irrigation ratio. The colored area represents the conditions under which irrigation has a purification effect on net nitrogen effluent loadings downstream for any $\alpha_{\mathrm{CI}}$ or $\chi_{c}$.

\section{RESULTS AND DISCUSSION \\ Water Balance}

We found that the amount of discharged water was smaller during cyclic irrigation periods compared to lake water irrigation periods (Table 2). Higher volumes of discharged water during lake water irrigation periods may partly be the result of the discharge of surplus irrigation water on fine days. We confirmed that the reuse of drainage water can reduce the inflow of water by lake water intake, because the amount of lake water intake was smaller during the cyclic irrigation period than during the lake water irrigation period.

We can estimate the amount of drainage water that was reused through cyclic irrigation from the difference between the volume of irrigation water and the volume of lake water intake. We found that the volume of reused drainage water was $792 \mathrm{~mm}, 864 \mathrm{~mm}$, and $878 \mathrm{~mm}$ with mean cyclic irrigation ratios of $0.82,0.90$, and 0.84 in 2007, 2008, and 2009 , respectively, during cyclic irrigation periods (Table 2). Because the lakeside inlet at the northern pump was closed in 2008 and 2009, ratios for these years represent estimates for a situation in which irrigation water had been taken from both water resources (the lake and the drainage canal) under cyclic irrigation. Lake water intake approximately equaled the volume of irrigation water during the lake water irrigation period, although the volume of reused drainage water by the operation of the southern pump was $50 \mathrm{~mm}, 47 \mathrm{~mm}$, and $22 \mathrm{~mm}$ in 2007, 2008, and 2009, respectively (Table 2). 
Table 2 - Water balance for the study district during irrigation periods.

\begin{tabular}{|c|c|c|c|c|c|c|}
\hline \multirow[b]{2}{*}{ Year } & \multirow[b]{2}{*}{ Period $^{\mathrm{a}}$} & \multicolumn{2}{|c|}{ Inflow $^{b}$} & \multicolumn{2}{|c|}{ Outflow $^{\mathrm{c}}$} & \multirow{2}{*}{$\begin{array}{c}\text { Irrigation water } \\
\text { (Pumped water) } \\
{[\mathrm{mm}]}\end{array}$} \\
\hline & & $\begin{array}{c}\mathrm{R} \\
{[\mathrm{mm}]}\end{array}$ & $\begin{array}{c}\text { LI } \\
{[\mathrm{mm}]}\end{array}$ & $\begin{array}{c}\text { ET } \\
{[\mathrm{mm}]}\end{array}$ & $\begin{array}{c}\mathrm{D} \\
{[\mathrm{mm}]}\end{array}$ & \\
\hline \multirow[t]{2}{*}{2007} & Cyclic irrigation & 405 & 173 & 277 & 277 & 965 \\
\hline & Lake water irrigation & 565 & 677 & 376 & 919 & 727 \\
\hline \multirow[t]{2}{*}{2008} & Cyclic irrigation & 481 & 100 & 277 & 285 & 964 \\
\hline & Lake water irrigation & 347 & 648 & 442 & 610 & 644 \\
\hline \multirow[t]{2}{*}{2009} & Cyclic irrigation & 280 & 168 & 287 & 124 & 1046 \\
\hline & Lake water irrigation & 331 & 605 & 365 & 583 & 618 \\
\hline
\end{tabular}

${ }^{\text {a }}$ Cyclic irrigation $=$ April $20-$ June 30; Lake water irrigation $=$ July $1-$ September 30.

${ }^{\mathrm{b}} \mathrm{R}$, rainfall; LI, lake water intake. ${ }^{\mathrm{c}} \mathrm{ET}$, evapotranspiration; D, discharged water.

\section{Nitrogen Effluent Loadings}

Our results show that, during the cyclic irrigation period, $\mathrm{N}$ effluent loadings increased mainly in association with rainfall events. During the lake water irrigation period, drainage water was discharged even on fine days (Fig. 4).

Nitrogen inputs and exports by rainfall, lake water intake, and discharged drainage water during the irrigation periods are listed in Table 3. We found that the $\mathrm{N}$ export during the cyclic irrigation period was smaller than during the lake water irrigation period, although weather conditions especially rainfall events during each irrigation period had a large influence on the amount of $\mathrm{N}$ exported. Mean $\mathrm{N}$ exports during the cyclic and lake water irrigation periods were $4.4 \mathrm{~kg} / \mathrm{ha}$ and $11.2 \mathrm{~kg} / \mathrm{ha}$, respectively.

\section{Effect of Cyclic Irrigation}

Nitrogen concentration ratios ranged from 1.6 to 5.5 under lake water irrigation $\left(\alpha_{C I}=0\right.$ $-0.16)$ and from 0.8 to 13.6 under cyclic irrigation $\left(\alpha_{C I}=0.62-1.0\right.$; Fig. 5), with $\chi_{c}$ typically higher under cyclic irrigation compared to lake water irrigation. Because $\chi_{c}$ is larger than one regardless of $\alpha_{C I}$ in almost all of our measurements, our results suggest that $\mathrm{N}$ concentration in water flowing through the district is not purified qualitatively and increases under both irrigation techniques. We believe this occurs because $\mathrm{N}$ is released from the sediment in the drainage canal. In the district, dredging of the sediments in the main drainage canal, other than in the southern area (about $100 \mathrm{~m}$ long), has not been conducted since 2004 when the canal was constructed. Therefore, we infer that the capacity of the drainage canal for storing new sediment has been reduced.

However, our results also suggest that the use of cyclic irrigation with high $\alpha_{\mathrm{CI}}$ has a net purification effect for any $\chi_{c}$, whereas the use of lake water irrigation has a net contamination effect when the surplus irrigation water ratio $\left(\alpha_{S W}\right)$ is large (e.g., $\alpha_{S W} \geq$ 0.7). The surplus amount or ratio of irrigation water could not be estimated because there were no hydrologic measurements for the paddy fields during this study. However, a previous study (Hama et al., 2010) suggested that the ratio of surplus irrigation water to total irrigation water was about $70 \%$ on the average during the irrigation period, varying from $30 \%$ to $90 \%$ daily. Therefore, lake water irrigation in the district may lead to net $\mathrm{N}$ contamination, even when $\alpha_{\mathrm{SW}}$ is low during the irrigation period. In contrast, cyclic irrigation has a net purification effect on $\mathrm{N}$ for possible $\alpha_{\mathrm{SW}}$. 


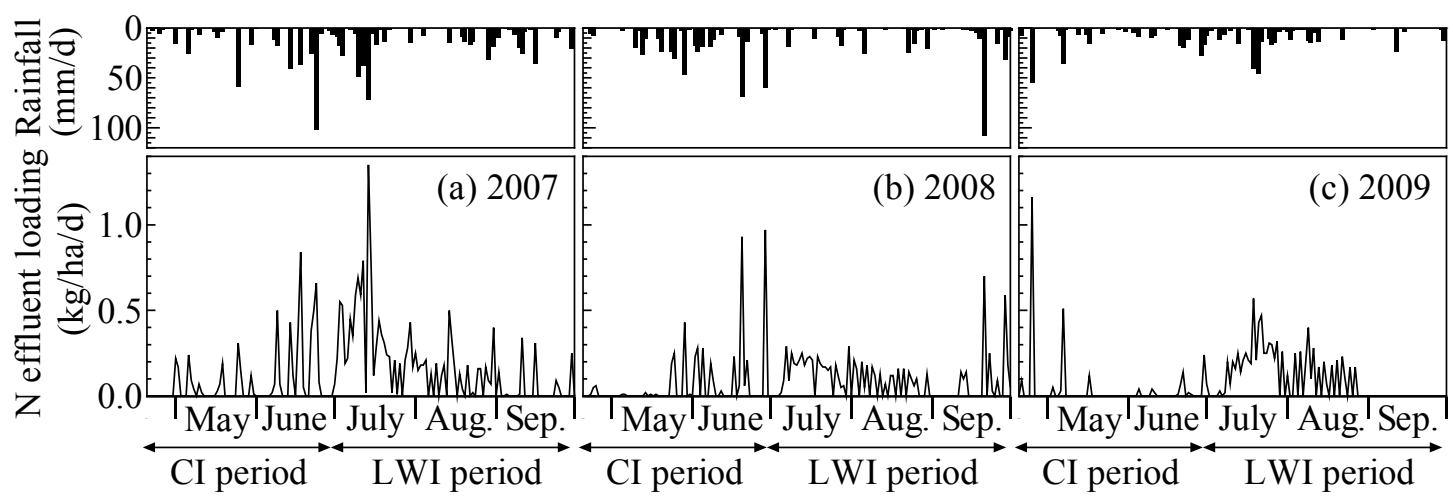

Fig. 4 - Daily variations in nitrogen effluent loadings during cyclic irrigation (CI) and lake water irrigation (LWI) periods in (a) 2007, (b) 2008 and (c) 2009.

Table 3 - Nitrogen inputs through rainfall (R) and lake water intake (LI) and exports through discharged water (D) during irrigation periods.

\begin{tabular}{|c|c|c|c|c|c|}
\hline \multirow[b]{2}{*}{ Year } & \multirow[b]{2}{*}{ Period $^{\mathrm{a}}$} & \multicolumn{2}{|c|}{ Inputs } & \multicolumn{2}{|c|}{ Exports } \\
\hline & & $\begin{array}{c}\mathrm{R} \\
{[\mathrm{kg} / \mathrm{ha}]}\end{array}$ & $\begin{array}{c}\text { LI } \\
{[\mathrm{kg} / \mathrm{ha}]}\end{array}$ & $\begin{array}{c}\mathrm{D} \\
{[\mathrm{kg} / \mathrm{ha}]}\end{array}$ & $\begin{array}{c}\text { net } \mathrm{N} \text { export } \\
{[\mathrm{kg} / \mathrm{ha}]}\end{array}$ \\
\hline \multirow[t]{2}{*}{2007} & Cyclic irrigation & 3.2 & 2.8 & 5.9 & -0.1 \\
\hline & Lake water irrigation & 4.5 & 4.6 & 16.1 & 7.0 \\
\hline \multirow[t]{2}{*}{2008} & Cyclic irrigation & 2.8 & 1.2 & 4.6 & 0.6 \\
\hline & Lake water irrigation & 2.0 & 2.1 & 8.8 & 4.7 \\
\hline \multirow[t]{2}{*}{2009} & Cyclic irrigation & 1.9 & 1.4 & 2.6 & -0.7 \\
\hline & Lake water irrigation & 2.2 & 3.3 & 8.7 & 3.2 \\
\hline
\end{tabular}

${ }^{\mathrm{a} C}$ Cyclic irrigation $=$ April $20-$ June 30 ; Lake water irrigation $=$ July $1-$ September 30.

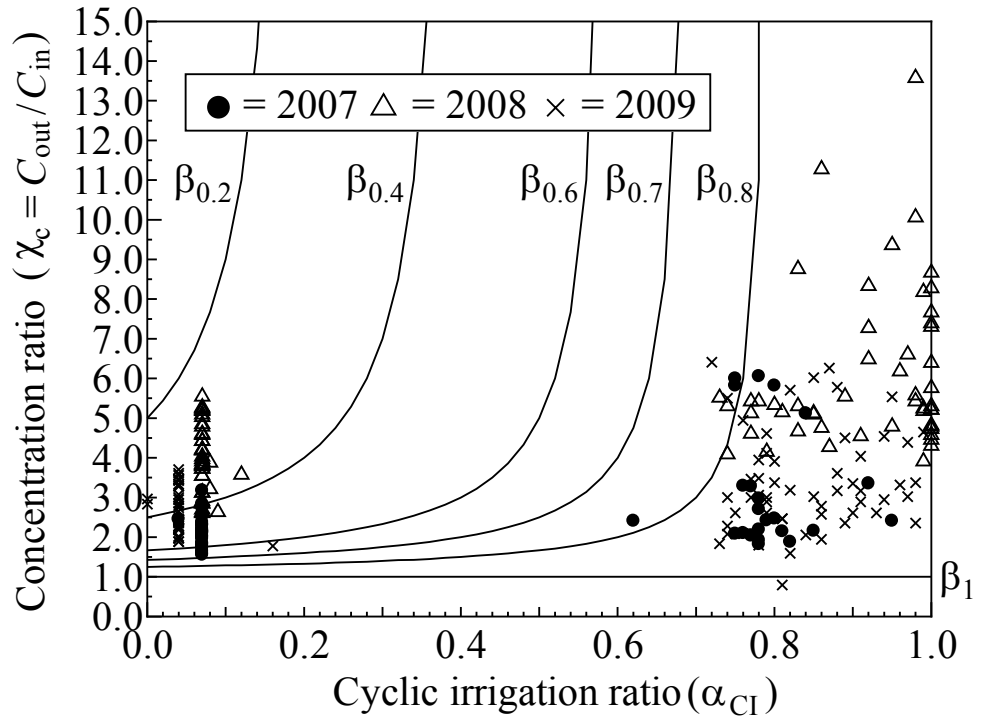

Fig. 5 - Relationship between the cyclic irrigation ratio and the concentration ratio considering various $\beta$ curves. Subscripts of $\beta$ represent the surplus irrigation ratio. 


\section{CONCLUSIONS}

We determined that the use of cyclic irrigation techniques, in which drainage water is reused, can effectively reduce $\mathrm{N}$ effluent loadings from paddy-field districts. The hydrological structure and the effect of cyclic irrigation systems can be characterized using three parameters: $N$ concentration ratio $\left(\chi_{\mathrm{c}}\right)$, cyclic irrigation ratio $\left(\alpha_{\mathrm{CI}}\right)$, and surplus irrigation water ratio $\left(\alpha_{\mathrm{SW}}\right)$. Furthermore, levels of $\alpha_{\mathrm{CI}}$ and $\alpha_{\mathrm{SW}}$ can act as strong indicators of the efficiency of water use in a paddy-field district. Our simple model may be applicable for assessing the effect of irrigation techniques on nutrient or suspended solid effluent loadings in other paddy-field districts.

\section{ACKNOWLEDGEMENTS}

We thank the Konohama Agricultural Union and the Shiga Prefectural Office for providing access to paddy plots for our investigation and for providing daily reports on water management and farming activity in those paddy fields. The research described in this paper was partly funded by the Grant-in-Aid for Scientific Research from the Japan Society for the Promotion of Science.

\section{REFERENCES}

Feng Y. W., Yoshinaga I., Shiratani E., Hitomi T. and Hasebe H. (2004) Characteristics and behavior of nutrients in a paddy field area equipped with a recycling irrigation system. Agric. Water Manage., 68(1), 47-60.

Feng Y. W., Yoshinaga I., Shiratani E., Hitomi T. and Hasebe H. (2005) Nutrient balance in a paddy field with a recycling irrigation system. Water Sci. Technol., 51(3-4), 151-157.

Hama T., Nakamura K. and Kawashima S. (2010) Effectiveness of cyclic irrigation in reducing suspended solids load from a paddy-field district. Agric. Water Manage., 97(3), 483-489.

Hitomi T., Yoshinaga I., Feng Y. W. and Shiratani E. (2006) Nitrogen removal function of recycling irrigation system. Water Sci. Technol., 53(2), 101-109.

Kaneki R. (2003) Reduction of effluent nitrogen and phosphorus from paddy fields. Paddy Water Environ., 1(3), 133-138.

Penman H. L. (1948) Natural evaporation from open water, bare soil and grass. Proc. Royal Soc. London Series A, 193(1032), 120-145.

Sakuratani T. and Horie T. (1985) Studies on evapotranspiration from crops, (1) On seasonal changes, varietal differences and the simplified methods of estimate in evapotranspiration of paddy rice. J. Agric. Meteorol., 41(1), 45-55. (in Japanese)

Shiratani E., Yoshinaga I., Feng Y. and Hasebe H. (2004) Scenario analysis for reduction of effluent load from an agricultural area by recycling the run-off water. Water Sci. Tech., 49(3), 55-62.

Takeda I., Fukushima A. and Tanaka R. (1997) Non-point pollutant reduction in a paddy-field watershed using a circular irrigation system. Water Res., 31(11), 2685-2692.

Takeda I. and Fukushima A. (2004) Phosphorus purification in a paddy field watershed using a circular irrigation system and the role of iron compounds. Water Res., 38(19), 4065-4074.

Takeda I. and Fukushima A. (2006) Long-term changes in pollutant load outflows and 
purification function in a paddy field watershed using a circular irrigation system. Water Res., 40(3), 569-578.

Zulu G., Toyota M. and Misawa S. (1996) Characteristics of water reuse and its effects on paddy irrigation system water balance and the riceland ecosystem. Agric. Water Manage., 31(3), 269-283. 